\title{
Regional Environmental Change refocuses on sustainability and the human-environment relationship
}

\author{
Wolfgang Cramer
}

Published online: 24 January 2013

(c) Springer-Verlag Berlin Heidelberg 2013

The journal Regional Environmental Change, founded by Wim Salomons in 1999, has published 72 papers in its thirteenth volume 2012, covering 925 printed pages. In this same year, its impact factor, as assessed by ThomsonReuters, has reached a value of 3.0, indicating that the work presented by our authors is reaching an attentive audience now. This is a good moment to reflect on some of the challenges for the journal and its editors as well as to report on some of the developments taking place.

First, it must be noted that neither the impact factor nor the number of published pages are themselves declared objectives of the journal. Instead, as our website indicates, its goal is “... to publish scientific research and opinion papers that improve our understanding of the extent of these [regional environmental] changes, their causes, their impacts on people, and the options for society to respond." One cannot really measure the achievement of this objective, so our readers will have to judge our success on a case by case basis. However, also, a number of submitting authors who have had manuscripts rejected with an "out of scope" response will be able to confirm that we are careful to constantly reassess the pertinence of any submission with respect to our stated goals.

For 2013, we intend to develop Regional Environmental Change in several ways. First, the team of editors has recently been reinforced, and we hope to see a few additional world class experts joining us shortly. Second, in response to the current backlog, the number of regular

W. Cramer $(\bowtie)$

Institut Méditerranéen de Biodiversité et d'Ecologie marine et continentale (IMBE), Aix-Marseille Université, UMR CNRS 7263/IRD 237, Bâtiment Villemin, Europole de l'Arbois-BP 80, 13545 Aix-en-Provence cedex 04, France

e-mail: wolfgang.cramer@imbe.fr issues will grow from four to six, with the expected number of pages to stay around 250 in each of them (one or several supplements will contain Special Issues). Besides regular papers, we will continue to publish occasional rapid communications as well as brief commentaries to earlier papers.

Based on our visibility and submission rate, we envisage to further enhance the content profile of the journal. A key feature remains the interdisciplinary approach as well as the focus on those regional studies that are of sufficient interest for scholars concerned with problems elsewhere (even well-written research reports with 'only' local interest have frequently been met with 'out of focus' rejections in the past). We will also remain open to a range of scales of studies, from small to large regions, and from changes over decades to centuries. Beyond this, we wish to strengthen the profile of contributions in the area of sustainable development and the support of associated policies, whether it is in the range of global policy instruments such as the Intergovernmental Platform on Biodiversity and Ecosystem Services (IPBES) or with respect to other fields of public or private decision-making. Finally, we expect the thriving discipline of social ecology, as it is now evolving a rich bouquet of regional studies (reviewed, for example, in a new book by Singh et al. $2013^{1}$ ) to deliver a new quality of rigorous investigations into the humanenvironment relationship at the regional level.

The amount of personal effort that goes into publishing 72 high-quality papers is rarely appreciated by the

\footnotetext{
1 Singh SJ, Haberl H, Chertow M, Mirtl M, Schmid M (eds.) 2013 Long Term Socio-Ecological Research-Studies in Society: Nature Interactions Across Spatial and Temporal Scales Springer Science + Business Media.
} 
academic community; hence, it is perhaps justified to briefly draw attention to this here. During the period July 2011-June 2012 (roughly corresponding to the time when most of the papers published 2012 were submitted), the editorial office received 331 original submissions from 60 different countries, plus 188 papers in various stages of revision: all of these were checked for technical and topical suitability and then assigned to some further operation. During this period, 980 invitations to review papers were issued, all of them after careful consideration of suitable reviewers and often with a personalised letter. For many reasons, 396 of these invitations were declined, and for 110 others, there was either no response or the review did not arrive in time for consideration.

Indeed, finding reviewers demands considerable effort for us, as it does for many journal editors. One cannot help noticing that, on the one hand, authors are quickly frustrated if reviews are not sent back to them quickly, or if those reviews contain minor errors, while, on the other hand, if the same persons are asked to review papers for a journal, they often decline, citing a broad range of reasons why, at this time, they are unable to review the manuscript. This creates an unsustainable situation against which many editors struggle with careful 'social engineering' of their pool of reviewers, with personalised invitations, delicate load balancing, small rewards and other measures. Nonetheless, the number of unsuccessful invitations remains a growing concern.

Another concern is that a few papers required straight rejections since they were identified as clear cases of plagiarism. It will require enhanced attention and smooth cooperation between journal editors to safeguard the intellectual property of scientific authors, despite the attempts by a small minority to effectively steal entire swathes of text from them. Regional Environmental Change will continue to apply a strict policy against such abuse.

The core of the success of any journal is surely the huge amount of effort that is being made by four key groups of people, and I take the opportunity to strongly acknowledge their contributions here.
First, of course, are the many authors who choose our journal as the outlet for the results of their scientific efforts.

Second, there is our team of currently 10 senior editors (Martin Beniston, Geneva, Switzerland, Elena M. Bennett, Montreal, Canada, Virginia Burkett, Many, USA, James D. Ford, Montreal, Canada, Helmut J. Geist, Erfurt, Germany, Ülo Mander, Tartu, Estonia, Anthony G. Patt, Vienna, Austria, Will Steffen, Canberra, Australia, Helga Weisz, Potsdam, Germany and Jintao Xu, Beijing, China) as well as a growing number of strongly dedicated Special Issue editors. The responsiveness of all these colleagues, and the serious attention they devote to every one of our contributions, never stop impressing me. During the last 2 years, two senior editors who had served the journal for a long time and in many roles have had to step down for other duties, and I wish to thank them particularly: Ruth Defries (New York) and Peter Burbridge (Newcastle). It was fascinating to work with you over those years, thank you very much!

Third, there are the many reviewers, including our editorial board members, who have contributed 473 excellent, constructive and often very detailed reviews during the reporting period 2011/2012 mentioned above.

And finally, there is the technical/editorial staff, first and foremost the managing editor Gabriele Götz at the Potsdam Institute for Climate Impact Research in Potsdam, Germany (a significant part of her time being graciously provided for the journal by her institute), plus many Springer staff members around the world: I mention here only our production editors Rajalakshmi Swaminathan and now Uma Parvathi in Chennai, India, and Margaret Deignan in Dordrecht, The Netherlands. The collective effort of these individuals provides the scientific community with a hugely important resource of primary knowledge.

I remain convinced that all this work is the essence of the human scientific endeavour and indeed useful, not only for the scientists who publish their findings or who cite material for new work, but also for the societal efforts to deal with environmental problems in a way that leads to more sustainable human-environment relationship.

Aix-en-Provence, December 2012 